\title{
Contagem de Células Somáticas em Amostras de Leite ${ }^{1}$
}

\section{Meiby Carneiro de Paula², Newton Pohl Ribas ${ }^{3}$, Humberto Gonzalo Monardes ${ }^{4}$, Julio Eduardo Arce ${ }^{5}$, Uriel Vinícius Cotarelli de Andrade ${ }^{6}$}

\begin{abstract}
RESUMO - Objetivou-se neste trabalho avaliar os fatores que influenciam a contagem de células somáticas (CCS) em amostras de leite de tanques e analisar a distribuição destas amostras nas classes de escore de células somáticas (ECS). Foram analisadas 257.540 amostras de leite de tanques, provenientes de 32.590 rebanhos de 18 indústrias de laticínios, localizadas nos Estados de Santa Catarina, Paraná e São Paulo, associadas ao Programa de Análise de Rebanhos Leiteiros do Paraná (PARLPR) da Associação Paranaense de Criadores de Bovinos da Raça Holandesa (APCBRH), no período de janeiro de 1999 a novembro de 2001. Empregou-se o procedimento PROC GLM, do SAS, para o estudo dos seguintes efeitos: micro-região, ano e mês de análise, idade da amostra e rebanho. A média e o desviopadrão amostral para a CCS foram de 486.812 e 401.547 células $/ \mathrm{mL}$, respectivamente. Todos os efeitos incluídos no modelo foram significativos sobre a CCS. Houve grande variação da CCS entre as micro-regiões, sendo a maior e menor médias ajustadas para CCS de 602.000 e 242.000 células $/ \mathrm{mL}$, respectivamente. No ano de 2001, foi observada a maior média para a CCS (483.000 células $/ \mathrm{mL}$ ). A maior média de CCS foi observada no mês de janeiro (497.000 células $/ \mathrm{mL}$ ) e a menor no mês de setembro (442.000 células/mL). O efeito de idade da amostra mostrou redução da CCS até o quarto dia e, a partir do sétimo dia, as médias sofreram grandes variações. Das amostras analisadas, 64,6\% apresentaram escore cinco ou maior.
\end{abstract}

Palavras-chave: CCS, escore de células somáticas, leite de tanques, qualidade do leite

\section{Somatic Cell Count in Milk Samples}

\begin{abstract}
The goal of this study was to evaluate somatic cell count (SCC) in bulk tank milk samples in the milk delivered to the industry by dairy farmers; also, to allot of the bulk tank milk samples in somatic cell score (SCS) class. Bulk tank milk samples are routinely analyzed at the central laboratory of the Programa de Análise de Rebanhos Leiteiros do Paraná (PARLPR) of the Holstein Association, state of Paraná, Brazil. The present study was on a data set of the PARLPR containing 257,540 bulk tank milk samples from 32,590 herds delivering milk to 18 dairy industries in the states of Santa Catarina, Paraná and São Paulo, analyzed between January 1999 and November 2001. General Linear Models procedures were used to study the effects of micro region, year and month of the test, herd and age of the sample on SCC in bulk tank milk samples. Mean and standard deviation for SCC samples in bulk tank milk samples were 486,812 and 401,547 cells $/ \mathrm{mL}$, respectively. All factors had a highly significant effect on the SCC. Micro regions were highly variable on the SCC, from 602,000 to 242,000 cells $/ \mathrm{mL}$. The highest means were observed in $2001(483,000$ cells $/ \mathrm{mL})$. Highest SCC means were observed in January $(497,000$ cells $/ \mathrm{mL})$ and lowest in September $(442,000$ cells $/ \mathrm{mL}$ ). The effect of age of the sample showed reduction in SCC levels until day four; after day seven samples were highly variable. Sixty-four percent of all samples showed a SCS of five or more.
\end{abstract}

Key Words: bulk tank milk, milk quality, SCC, somatic cell score

\section{Introdução}

A contagem de células somáticas (CCS) no leite, um meio de diagnóstico da mastite subclínica, é aceita internacionalmente como a medida padrão para determinar a qualidade do leite cru (Harmon, 1998; Philpot, 1998; Smith \& Hogan, 1998; Ribas, 1999).
O entendimento da dinâmica da CCS em leite de tanques é um importante passo para melhoria da qualidade do leite (Schukken et al., 1992b; Schukken et al., 1993). Elevadas CCS em leite de tanques provocam perdas na produção e a manutenção de baixas CCS indica boa saúde da glândula mamária dos animais do rebanho (Schukken et al., 1990).

\footnotetext{
${ }^{1}$ Parte da dissertação de mestrado do primeiro autor, Pós-Graduação em Ciências Veterinárias da UFPR, Área de Concentração Produção Animal.

2 Zootecnista, M.Sc., Doutoranda do Curso de Pós-Graduação em Zootecnia da Universidade Estadual de Maringá, Área de Concentração Produção Animal. Av. Colombo, 5749 - Bloco 32 - Sala 3, CEP: 87020-900, Maringá-PR. E.mail: meiby@zipmail.com.br

3 Méd. Vet., M.Sc., Professor do Departamento de Zootecnia, UFPR. E.mail: npribas@pr.gov.br

${ }^{4}$ Eng. Agr., M.Sc., Ph.D., Professor Department Animal Science, McGill University, Montreal, Canadá

${ }^{5}$ Eng. Florestal, M.Sc., Ph.D., Professor do Departamento de Ciências Florestais, UFPR.

${ }^{6}$ Méd. Vet., M.Sc., Professor da Universidade Tuiuti do Paraná.
} 
Segundo Wells \& Ott (1998), razões para monitorar a CCS em leite de tanques incluem a demanda de consumidores por produtos de alta qualidade, a necessidade de processamento do leite cru de qualidade e a pressão do mercado internacional por produtos de qualidade. Altas CCS afetam a composição do leite e o tempo de vida de prateleira dos derivados, causando grandes prejuízos para a indústria de laticínios.

No Brasil, a análise da CCS foi introduzida em 1991 pelo Programa de Análise de Rebanhos Leiteiros do Paraná (PARLPR), da Associação Paranaense de Criadores de Bovinos da Raça Holandesa (APCBRH).

Objetivou-se, neste trabalho, avaliar os fatores que influenciam a CCS em amostras de leite de tanques e analisar a distribuição destas amostras nas classes de escore de células somáticas (ECS).

\section{Material e Métodos}

Os dados utilizados neste estudo foram extraídos do arquivo de dados do PARLPR, localizado em Curitiba, Paraná, desenvolvido por intermédio do convênio entre a APCBRH e a UFPR.

Para o estudo da CCS em leite de tanques, 257.540 amostras extraídas de 32.590 rebanhos de 18 indústrias de laticínios, localizadas em 21 microregiões, nos Estados de Santa Catarina, Paraná e São Paulo foram analisadas no período de janeiro de 1999 a novembro de 2001.

As amostras de leite de tanques foram coletadas quinzenalmente nas propriedades leiteiras e permaneceram refrigeradas até chegarem à indústria, onde foram acondicionadas em frascos padronizados (70 mL) utilizando o conservante bronopol (2-bromo2-nitropropano-1,3-diol) e enviadas para o Laboratório Centralizado de Análise do Leite do PARLPR.

$\mathrm{O}$ número de dias decorridos entre a coleta de leite na fazenda e sua análise no laboratório foi definido como a idade da amostra.

As análises da CCS foram realizadas por citometria de fluxo, no equipamento Somacount $500 \AA^{1}$, com capacidade para a análise de 500 amostras por hora. A CCS foi obtida a partir da leitura do equipamento de contagem eletrônica de células somáticas, em 1.000 células $/ \mathrm{mL}$.

As informações da CCS foram retiradas do banco de dados original do PARLPR e armazenadas em um arquivo computacional.

R. Bras. Zootec., v.33, n.5, p.1303-1308, 2004
Para a análise dos dados, empregou-se o programa computacional SAS (1991).

O modelo matemático utilizado foi:

$$
\mathrm{Y}_{\mathrm{ijkl}}=\mu+\mathrm{M}_{\mathrm{i}}+\mathrm{A}_{\mathrm{j}}+\mathrm{I}_{\mathrm{k}}+\mathrm{R}_{\mathrm{l}}+\mathrm{e}_{\mathrm{ijkl}}
$$

em que: $Y_{\text {ijkl }}=$ observação referente à CCS de amostras de leite de tanques; $\mu=$ média geral; $\mathrm{M}_{\mathrm{i}}=$ efeito da micro-região $\mathrm{i}(\mathrm{i}=1,2, \ldots, 21)$; $A_{j}=$ efeito do ano e mês de análise $\mathrm{j}(\mathrm{j}=1,2, \ldots, 35)$; $\mathrm{I}_{\mathrm{k}}=$ efeito da idade da amostra $\mathrm{k}(\mathrm{k}=1,2, \ldots, 14) ; \mathrm{R}_{\mathrm{l}}$ : efeito do rebanho $1,(1=1,2, \ldots, 32.590) \mathrm{e} \mathrm{e}_{\mathrm{ijkl}}=$ erro aleatório associado a cada observação $\mathrm{Y}_{\mathrm{i} \mathrm{j} \mathrm{kl}}$.

O ECS foi obtido pela equação ECS $=\log _{2}(\mathrm{CCS} /$ $100)+3$ (Shook, 1982).

\section{Resultados e Discussão}

A média e o desvio-padrão amostral da CCS foram de 486.812 e 401.547 células/mL, respectivamente.

A média da CCS em leite de tanques observada foi superior àquelas encontradas por Franks (2001), que observou a menor média na Suíça (112.000 células $/ \mathrm{mL}$ ) e maior em Israel (382.000 células $/ \mathrm{mL}$ ), e Godkin (1999), que, na Província de Ontário, Canadá, encontrou média de 250.000 células/mL.

No Brasil, Machado et al. (2000) avaliaram 4.785 amostras de leite de tanques para CCS de rebanhos localizados nos Estados de São Paulo e no sul de Minas Gerais e registraram média e desvio-padrão amostral de 505.000 e 593.000 células $/ \mathrm{mL}$, respectivamente, superiores aos valores verificados neste estudo.

A média da CCS em leite de tanques atingida neste estudo é alta quando comparada a países de pecuária leiteira desenvolvida, o que reflete pouco cuidado dos produtores com relação à sanidade da glândula mamária e falta de estímulo por parte das indústrias em estabelecer programas de pagamento de leite por qualidade com base na CCS.

Os resultados da análise de variância da CCS em amostras de leite de tanques encontra-se na Tabela 1. Todos os efeitos incluídos no modelo foram significativos $(\mathrm{P}<0,01)$ sobre a CCS.

As estimativas das médias ajustadas pelo método dos quadrados mínimos da CCS e os respectivos erros-padrão para as 21 micro-regiões estudadas estão descritos na Tabela 2. A menor média foi de 242.000 células $/ \mathrm{mL}$ e a maior de 602.000 células $/ \mathrm{mL}$. Houve grande variação nas médias da CCS em leite de tanques entre as micro-regiões. Ott et al. (1999) e Norman et al. (2001), nos Estados Unidos, também encontraram grandes diferenças na CCS do leite de 
tanques entre as regiões, em decorrência das diferenças de clima, uma vez que as regiões de clima seco tiveram as menores médias de CCS e as de clima quente e úmido, as maiores.

$\mathrm{Na}$ Figura 1, encontram-se as estimativas das médias ajustadas pelo método dos quadrados mínimos da CCS, segundo o mês de análise. O maior valor foi observado no mês de janeiro (497.000 células $/ \mathrm{mL}$ ) e o menor, no mês de setembro (442.000 células $/ \mathrm{mL}$ ).

Harmon \& Reneau (1993), Harmon (1998), Ott et al. (1999) e Pritchard et al. (2001) também relataram resultados semelhantes, ao observarem que as maiores médias de CCS ocorreram no verão e as menores no inverno.

Segundo Harmon \& Reneau (1993) e Harmon (1998), o verão é o período com a maior incidência de mastite clínica, principalmente a de origem ambiental. O estresse de altas temperaturas e umidade também aumentam a susceptibilidade às infecções e aumentam o número de patógenos aos quais as vacas são expostas.

$\mathrm{Na}$ Tabela 3, estão apresentadas as estimativas das médias ajustadas pelo método dos quadrados mínimos da CCS e os respectivos erros-padrão para o efeito de ano de análise. A maior média para a CCS foi observada no ano de 2001 (483.000 células/mL).

Schukken et al. (1990), Schukken et al. (1992a), Schukken et al. (1993), Sargeant et al. (1998) e Godkin

Tabela 1 - Resumo da análise de variância da contagem de células somáticas (CCS) em amos-

tras de leite de tanques
Table 1 - Variance analysis summary of somatic cell count (SCC) in bulk tank milk samples

\begin{tabular}{|c|c|c|}
\hline Fonte de variação & G & $\begin{array}{c}\text { Quadrado médio } \\
\text { Mean square }\end{array}$ \\
\hline Source of variation & $D F$ & $\begin{array}{l}\text { CCS } \\
\text { SCC }\end{array}$ \\
\hline $\begin{array}{l}\text { Micro-região } \\
\text { Micro region }\end{array}$ & 20 & $53.996 .008,57 * *$ \\
\hline $\begin{array}{l}\text { Ano e mês de análise } \\
\text { Year and month of the test }\end{array}$ & 34 & $12.315 .330,05^{* *}$ \\
\hline $\begin{array}{l}\text { Idade de amostra } \\
\text { Age of the sample }\end{array}$ & 13 & $5.098 .499,33 * *$ \\
\hline $\begin{array}{l}\text { Rebanho } \\
\text { Herd }\end{array}$ & 32.589 & $590.279,57 * *$ \\
\hline $\begin{array}{l}\text { Resíduo } \\
\text { Error }\end{array}$ & 224.883 & $92.154,87$ \\
\hline $\begin{array}{l}\mathrm{R}^{2} \\
\mathrm{CV}(\%)\end{array}$ & $\begin{array}{c}0,5009 \\
62,3589\end{array}$ & \\
\hline
\end{tabular}

$\mathrm{GL}=$ grau de liberdade $(D F=$ degree of freedom $)$.

$\mathrm{R}^{2}=$ coeficiente de determinação (coefficient of determination).

$\mathrm{CV}=$ coeficiente de variação (coefficient of variation).

${ }^{* *}=(P<0,01)\left(^{* *}=P<.01\right)$.

\section{R. Bras. Zootec., v.33, n.5, p.1303-1308, 2004}

(1999) também estudaram o efeito do ano de análise sobre a CCS em amostras de leite de tanques e observaram redução na CCS ao longo dos anos. Espera-se que, com a implantação do Programa Nacional de Melhoria da Qualidade do Leite no Brasil, a CCS apresente comportamento semelhante.

A CCS sofreu grande influência do efeito de idade da amostra. Do primeiro ao quarto dia de idade da amostra houve redução nos valores da CCS (Tabela 4), contrastando com Kennedy et al. (1982), que observaram que os valores da CCS permaneceram praticamente inalterados nos três primeiros dias e reduziram com o aumento da idade da amostra, com Ostrensky (1999), que encontrou aumento nos valores de CCS, e com Monardes et al. (1996), que não verificaram efeito significativo da idade de amostra sobre a CCS. Ostrensky (1999) e Kennedy et al. (1982) utilizaram, como conservante do leite, o dicromato de potássio em vez do bronopol. A causa da diminuição da CCS com o avançar da idade da amostra, apesar de não ter sido investigada neste estudo e nos demais trabalhos citados, pode ser atribuída à lise celular.

No sétimo dia, as médias ajustadas para a CCS tiveram redução de 9,98\% em relação ao primeiro dia de análise. Após o sétimo dia, houve grande variação nos valores. As oscilações observadas são resultado do número de observações em cada uma destas

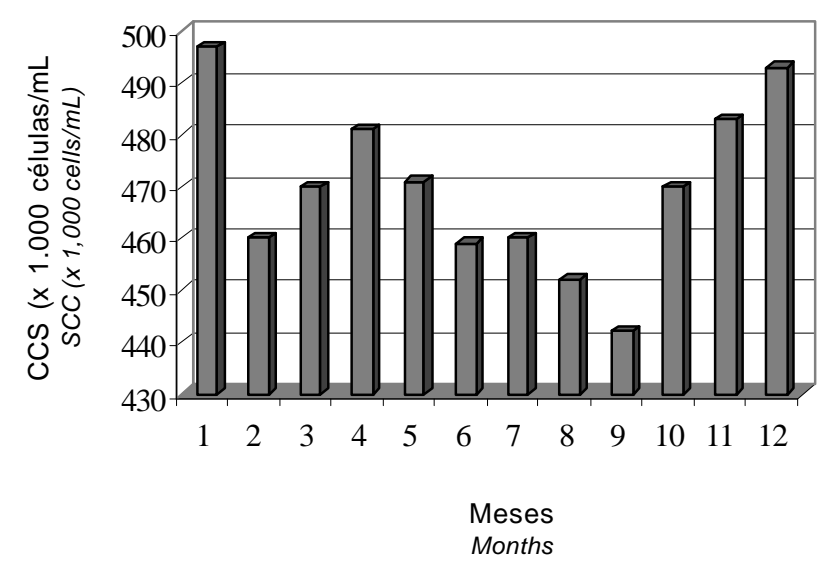

Figura 1 - Médias estimadas da contagem de células somáticas (CCS) em amostras de leite de tanques, segundo o mês de análise.

Figure 1 - Estimate means of somatic cell count (SCC) in bulk tank milk samples, by month of the test. 
classes e podem indicar uma perda da confiabilidade das análises realizadas com mais de sete dias após coleta. Kennedy et al. (1982) também observaram declínio de $28 \%$ na CCS e Ostrensky (1999), de $10,7 \%$, do primeiro ao oitavo dia.

Embora a idade da amostra afete significativamente a CCS, apenas $29,2 \%$ das amostras de leite de tanques deste trabalho foram analisadas até o terceiro dia e $78,8 \%$ até o sétimo dia. Monardes et al. (1996) relataram que, no Canadá, $93 \%$ das amostras foram analisadas até o terceiro dia e $99 \%$ até o sétimo dia após a coleta. As amostras analisadas nos primeiros dias após a coleta são as que apresentam valores mais próximos do verdadeiro.

Emanuelson \& Funke (1991); Allore et al. (1997); Wells \& Ott (1998); Ott et al. (1999) e Norman et al.

Tabela 2 - Número de observações (N), médias estimadas e respectivos erros-padrão da contagem de células somáticas (CCS) em amostras de leite de tanques, segundo a micro-região

Table 2 - Number of observations $(N)$, estimated means and respective standard errors of somatic cell count (SCC) in bulk tank milk samples, by micro region

\begin{tabular}{cccc}
\hline & & \multicolumn{2}{c}{ CCS (x 1.000 células/mL) } \\
Micro-região & $\mathrm{N}$ & \multicolumn{2}{c}{ SCC (x 1,000 cells $/ \mathrm{mL})$} \\
\cline { 3 - 4 } Micro region & $N$ & $\begin{array}{c}\text { Médias } \\
\text { Means }\end{array}$ & $\begin{array}{c}\text { Erros-padrão } \\
\text { Standard error }\end{array}$ \\
\hline 1 & & 490 & 18,43 \\
2 & 492 & 521 & 16,47 \\
3 & 836 & 402 & 13,08 \\
4 & 4.753 & 451 & 6,29 \\
5 & 1.107 & 593 & 12,22 \\
6 & 920 & 242 & 13,61 \\
7 & 23.514 & 574 & 3,33 \\
8 & 1.596 & 376 & 10,17 \\
9 & 2.172 & 510 & 8,77 \\
10 & 2.165 & 502 & 8,81 \\
11 & 3.063 & 460 & 7,55 \\
12 & 3.372 & 407 & 7,79 \\
13 & 19.658 & 356 & 3,69 \\
14 & 4.641 & 477 & 6,23 \\
15 & 5.428 & 602 & 5,91 \\
16 & 25.186 & 516 & 3,39 \\
17 & 7.682 & 413 & 5,07 \\
18 & 21.994 & 525 & 3,51 \\
19 & 28.961 & 435 & 2,87 \\
20 & 36.460 & 374 & 3,73 \\
21 & 62.609 & 520 & 2,82 \\
\hline Total & 257.540 & & \\
Total & & & \\
\hline & & &
\end{tabular}

(2001), assim como neste trabalho, constataram influência do efeito de rebanho sobre a CCS em amostras de leite de tanques. Esses autores relataram que o nível de produção e o tamanho dos rebanhos afetam a CCS. Segundo Emanuelson \& Funke (1991), o aumento na produção total de leite do rebanho ocasionou maior incidência de mastite. Ott et al. (1999) observaram decréscimo na CCS com a evolução no tamanho do rebanho.

A distribuição de frequiência das amostras de leite de tanques para CCS nas classes de ECS encontra-se na Tabela 5. Das amostras analisadas, 64,6\% se enquadram no escore cinco ou maior. Estes resultados estão abaixo dos almejados pelos serviços de controle de rebanhos leiteiros dos Estados Unidos e Canadá, que têm como meta atingir que $80 \%$ de seus rebanhos apresentem, no máximo, escore linear três (Ribas, 1999).

A grande frequiência de amostras encontradas no escore linear cinco ou maior reflete elevado nível de infecção dos rebanhos, comprovando a importância de as indústrias implementarem programas de pagamento que valorizem a qualidade do leite.

Tabela 3 - Número de observações (N), médias estimadas e respectivos erros-padrão da contagem de células somáticas (CCS) em amostras de leite de tanques, segundo o ano de análise

Table 3 - Number of observations ( $N$ ), estimate means and respective standard errors of somatic cell count (SCC) in bulk tank milk samples, by year of the test

\begin{tabular}{cccc}
\hline \multirow{2}{*}{ Ano } & $\mathrm{N}$ & \multicolumn{2}{c}{ CCS $(\mathrm{x} 1.000$ células $/ \mathrm{mL})$} \\
\cline { 3 - 4 } Year & $N$ & $\begin{array}{c}\text { Médias }(\times 1,000 \text { cells } / \mathrm{mL}) \\
\text { Means }\end{array}$ & $\begin{array}{c}\text { Erros-padrão } \\
\text { Standard error }\end{array}$ \\
\hline 1999 & 77.858 & 464 & 2,85 \\
2000 & 90.127 & 463 & 2,97 \\
2001 & 89.555 & 483 & 2,97 \\
Total & 257.540 & & \\
Total & & & \\
\hline
\end{tabular}


Tabela 4 - Número de observações (N), médias estimadas e respectivos errospadrão da contagem de células somáticas (CCS) em amostras de leite de tanques, segundo a idade da amostra

Table 4 - Number of observations $(N)$, estimated means and respective standard errors of somatic cell count (SCC) in bulk tank milk samples, by sample age

\begin{tabular}{|c|c|c|c|}
\hline \multirow{2}{*}{$\begin{array}{l}\text { Idade da amostra (dias) } \\
\text { Age of the sample (days) }\end{array}$} & \multirow{2}{*}{$\begin{array}{l}\mathrm{N} \\
N\end{array}$} & \multicolumn{2}{|c|}{$\begin{array}{c}\text { CCS (x } 1.000 \text { células/mL) } \\
\text { SCC (x 1,000 cells } / m L)\end{array}$} \\
\hline & & $\begin{array}{l}\text { Médias } \\
\text { Means }\end{array}$ & $\begin{array}{l}\text { Erros-padrão } \\
\text { Standard errors }\end{array}$ \\
\hline 1 & 2.337 & 531 & 8,53 \\
\hline 2 & 36.222 & 502 & 2,87 \\
\hline 3 & 36.709 & 491 & 2,80 \\
\hline 4 & 30.611 & 469 & 2,99 \\
\hline 5 & 71.344 & 470 & 2,54 \\
\hline 6 & 21.450 & 473 & 3,50 \\
\hline 7 & 4.369 & 478 & 6,42 \\
\hline 8 & 3.826 & 444 & 6,74 \\
\hline 9 & 21.768 & 489 & 4,35 \\
\hline 10 & 3.366 & 492 & 7,12 \\
\hline 11 & 18.866 & 455 & 4,09 \\
\hline 12 & 4.864 & 468 & 6,24 \\
\hline 13 & 1.447 & 370 & 12,60 \\
\hline 14 & 361 & 365 & 21,16 \\
\hline $\begin{array}{l}\text { Total } \\
\text { Total }\end{array}$ & 257.540 & & \\
\hline
\end{tabular}

Tabela 5 - Distribuição das amostras de leite de tanques (N) em classes de escore de células somáticas (ECS)

Table 5 - Distribution of bulk tank milk samples $(N)$ by classes of score somatic cell count (SCS)

\begin{tabular}{|c|c|c|c|c|}
\hline $\begin{array}{l}\text { ECS } \\
S C S\end{array}$ & $\begin{array}{l}\text { Variação da } C_{C C S}{ }^{1} \\
\text { Variation of } S C C^{1}\end{array}$ & $\begin{array}{l}\mathrm{N} \\
N\end{array}$ & $\%$ & $\begin{array}{l}\% \text { Acumulada } \\
\% \text { Accumulated }\end{array}$ \\
\hline 0 & 0 a 17 & 611 & 0,2 & 0,2 \\
\hline 1 & 18 a 34 & 2.160 & 0,8 & 1,0 \\
\hline 2 & 35 a 70 & 6.874 & 2,7 & 3,7 \\
\hline 3 & 71 a 140 & 23.066 & 9,0 & 12,7 \\
\hline 4 & 141 a 282 & 58.457 & 22,7 & 35,4 \\
\hline 5 & 283 a 565 & 89.977 & 34,9 & 70,3 \\
\hline 6 & 566 a 1.130 & 59.046 & 22,9 & 93,2 \\
\hline 7 & $1.131 \mathrm{a} 2.262$ & 15.605 & 6,1 & 99,3 \\
\hline 8 & $2.263 \mathrm{a} 4.525$ & 1.744 & 0,7 & 100 \\
\hline 9 & $>4.525$ & 0 & 0 & - \\
\hline $\begin{array}{l}\text { Total } \\
\text { Total }\end{array}$ & 257.540 & 100 & & - \\
\hline
\end{tabular}

1 (x 1.000 células $/ \mathrm{mL})($ x 1,000 cells $/ \mathrm{mL})$.

\section{Conclusões}

A média estimada para a CCS em amostras de leite de tanques é elevada, quando comparada à de países de pecuária leiteira mais desenvolvida.

Os efeitos de micro-região, ano e mês de análise, idade da amostra e rebanho foram significativos sobre as três características estudadas.
Do total de amostras analisadas, $64,6 \%$ apresentaram escore linear cinco ou maior.

\section{Agradecimento}

Ao Programa de Análise de Rebanhos Leiteiros do Paraná do convênio entre a Associação Paranaense de Criadores de Bovinos da Raça Holan- 
desa e a Universidade Federal do Paraná, pela concessão do banco de dados e pelo apoio, que possibilitaram o desenvolvimento deste estudo.

\section{Literatura Citada}

ALlORE, H.G.; OLTENACU, P.A.; ERB, H.N. Effects of season, herd size, and geographic region on the composition and quality of milk in the Northeast. Journal of Dairy Science, v.80, n.11, p.3040-3049, 1997.

EMANUELSON, U.; FUNKE, H. Effect of milk yield on relationship between bulk milk somatic cell count and prevalence of mastitis. Journal of Dairy Science, v.74, n.8, p.2479-2483, 1991.

FRANKS, B. International milk quality. Disponível em: <http://www.2nzdairy.co.nz:82/ suppliernews / july2001.pdf> Acesso em: 24 out. 2001.

GODKIN, A. Monitoring and controlling mastitis: progress in Ontario. In: NATIONAL MASTITIS COUNCIL REGIONAL MEETING, 1999, Waterloo. Proceedings... Madison: National Mastitis Council, 1999. p.1-9.

HARMON, R.J. Somatic cell counts: Myths vs reality. In: NATIONAL MASTITIS COUNCIL REGIONAL MEETING, 37., 1998, Bellevue. Proceedings... Madison: National Mastitis Council, 1998. p.40-50.

HARMON, R.J.; RENEAU, J.K. Factors affecting somatic cell counts in milk. In: NATIONAL MASTITIS COUNCIL ANnUAl MEeting, 32., 1993, Arlington. Proceedings... Madison: National Mastitis Council, 1993. p.48-57.

KENNEDY, B.W.; SETHAR, M.S.; TONG, A.K.W. et al. Environmental factors influencing test-day somatic cell counts in Holsteins. Journal of Dairy Science, v.65, n.2, p.275-280, 1982 .

MACHADO, P.F.; PEREIRA, A.R.; SARRÍES, G.A. Composição do leite de tanques de rebanhos brasileiros distribuídos segundo sua contagem de células somáticas. Revista Brasileira de Zootecnia, v.29, n.6, p.1883-1886, 2000.

MONARDES, H.G; MOORE, R.K.; CORRIGAN, B. et al. Milk preservatives under different systems of samples storage in Quebec, Canada. Journal of Food Protection, v.59, n.2, p.151-154, 1996.

NORMAN, H.D.; MILLER, R.H.; WRIGHT, J.R. et al. Herd and state means for somatic cell count for dairy herd improvement. Disponível em: <http://www.nalusda.gov/ ttic/tektran/data/0000106436.html> Acesso em: 03 nov. 2001.

OSTRENSKY, A. Efeitos de ambientes sobre a contagem de células somáticas no leite de vacas da raça holandesa no Paraná. Curitiba: Universidade Federal do Paraná, 1999. 114p. Dissertação (Mestrado em Ciências Veterinárias) Universidade Federal do Paraná, 1999.

OTT, S.L.; WELLS, S.J.; SMITH, M.A. Bulk tank somatic cell counts of U.S. milk supply, 1997. In: NATIONAL MASTITIS COUNCIL ANNUAL MEETING, 38., 1999, Arlington. Proceedings... Madison: National Mastitis Council, 1999. p.154-156.
PHILPOT, W.N. Importância da contagem de células somáticas e outros fatores que afetam a qualidade do leite. In: SIMPÓSIO INTERNACIONAL SOBRE QUALIDADE DO LEITE, 1., 1998, Curitiba. Anais... Curitiba, 1998. p.28-35.

PRITCHARD, D.E.; ANDERSON, K.L.; MYERS, Z.H. Seasonal patterns of bulk tank milk somatic cell counts. Disponível em: <http://www.cals.ncsu.edu/na_sci/extension/ dairy/winter\%202000\%20word\%2oversion\%202.htm> Acesso em: 3 mar. 2001.

RIBAS, N.P. Importância da contagem de células somáticas para a saúde da glândula mamária e qualidade do leite. In: $4^{\circ}$ SIMPÓSIO INTERNACIONAL SOBRE PRODUÇÃO INTENSIVA DE PRODUÇÃO DE LEITE, 4., 1999, Caxambu. Anais... São Paulo: Instituto Fernando Costa, 1999. p.77-87.

SARGEANT, J.M.; SCHUKKEN, Y.H.; LESLIE, K.E. Ontario bulk milk somatic cell count reduction program: progress and outlook. Journal of Dairy Science, v.81, n.6, p.1545-1554, 1998.

STATISCAL ANALYSES SYSTEM - SAS. User's guide: statistics. 3.ed. Cary: 1991.

SCHUKKEN, Y.H.; BUURMAN, J.; BRAND, A. et al. Our industry today: population Dynamics of bulk milk somatic cell counts. Journal of Dairy Science, v.73, n.5, p.13431350, 1990.

SCHUKKEN, Y.H.; LESLIE, K.E.; WEERSINK, A.J. et al. Ontario bulk milk somatic cell reduction program. 1. Impact on somatic cell counts and milk quality. Journal of Dairy Science, v.75, n.12, p.3352-3358, 1992a.

SCHUKKEN, Y.H.; LESLIE, K.E.; WEERSINK, A.J. et al. Ontario bulk milk somatic cell reduction program. 2. Dynamics of bulk milk somatic cell counts. Journal of Dairy Science, v.75, n.12, p.3359-3366, $1992 b$.

SCHUKKEN, Y.H.; WEERSINK, A.; LESLIE, K.E. et al. Dynamics and regulation of bulk milk somatic cell counts. Canadian Journal Veterinary Research, v.57, p.131$135,1993$.

SHOOK, G.E. Approaches to summarizing somatic cell count which improve interpretability. In: NATIONAL MASTITIS COUNCIL ANNUAL MEETING, 21., 1982, Pennsylvania. Proceedings... Madison: National Mastitis Council, 1982. p.150-166.

SMITH, K.L.; HOGAN, J.S. Milk quality - a worldwide perspective. In: NATIONAL MASTITIS COUNCIL ANNUAL MEETING, 37., 1998, St. Louis. Proceedings... Madison: National Mastitis Council, 1998. p.3-9.

WELLS, S.J.; OTT, S.L. What is the current milk quality in the US? In: NATIONAL MASTITIS COUNCIL ANNUAL MEETING, 37., 1998, St. Louis. Proceedings... Madison: National Mastitis Council, 1998. p.10-18.

Recebido em: 13/03/03

Aceito em: 24/11/03 